\title{
Infrared thermography, a tool serving the societal stakes: measurement methods, traceability, pro and cons
}

\author{
Jean-Rémy FILTZ ${ }^{1}$, Véronique LE SANT ${ }^{1}$, Sylvain PIERRARD ${ }^{1}$, Romain CHASSEIGNE ${ }^{1}$, \\ Romain MORTELETTE ${ }^{1}$, Didier BASSI ${ }^{1}$, Sabrina LECADRE ${ }^{1}$ \\ 1-Laboratoire national de métrologie et d'essais, 29, Avenue Roger Hennequin, 78190 Trappes, Paris Area, France
}

\begin{abstract}
Résumé. Dans le cadre du contexte de lutte contre le réchauffement climatique, les pouvoirs publics locaux font appel aux services du LNE pour réaliser des cartographies aériennes ou terrestres de leurs territoires respectifs. L'objectif est d'identifier les déperditions de chaleur par les toits et les façades des bâtiments. Ce papier décrit les méthodes de mesure et de traitement développées au LNE, spécialement dans le cas d'une thermographie aérienne. Ceci inclut les règles de base d'une mission, la traçabilité, l'intérêt de cette technique ainsi que les limitations opérationnelles.
\end{abstract}

\section{Introduction}

The fight against climate change and associated risks are one set of the crucial subjects of international, regional and national policies, which aims to reduce emissions of greenhouse gases and to fully prepare the populations to the consequences of this climatic evolution.

Among different actions in France, different actors, meeting within the framework of so-called work of the "Grenelle de l'environnement I and II" have converged towards the need to implement and to generalize the National Climate-Energy Territorial Plan at a more local level (e.g. Agenda 21).

Such action aims at enhancing national policies to better fight against climate change and contribute to achieving international goals to which France has subscribed [1].

This is within this context that local authorities such as towns or great urban centres ask LNE services to perform traceable aerial or terrestrial infrared mappings of their respective

territory. The objective is to target and identify heat losses from roofs or facades of buildings.

This analytical tool enables to help local players to optimize their energy renovation policy.
In the following chapters, this paper deals with the measurement and analysis methods implemented at LNE, especially in the case of an aerial thermography.

\section{Infrared thermography}

Infrared thermography becoming today a routine tool is an optical viewing technique, based on the thermal radiation emitted by any object, whatever its temperature.

This technique uses thermal cameras (also called infrared cameras), equipped with detectors especially adapted to the spectral wavelength band suitable for the dedicated application.

The output data obtained are used in many applications.

For instance; expertise or energy audit of buildings (Figure 1), heat network detection, monitoring of mechanical or electrical processes, electronics, monitoring of mining slag heaps, and safety of property and persons or still for defense applications.
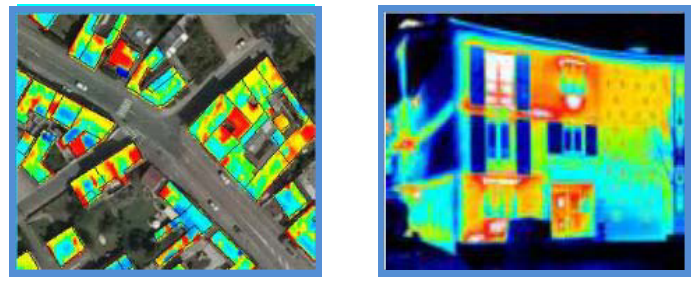

Figure 1: Heat losses from buildings 


\section{Preparing a mission}

In the following chapters, the paper describes the main points to be issued for a successful aerial mission.

\subsection{Calibration procedure}

Before starting any new missions season (Year $\mathrm{n} /$ Year $\mathrm{n}+1$ ), the infrared remote sensing system (in the next pages, this system will be called IR scanner) is periodically calibrated against $\mathrm{SI}$ traceable standard sources.

In order to be in a similar position as during the aerial mission, the IR scanner is vertically setup successively in front of two calibrated flat black bodies $\mathrm{CN} 1$ and $\mathrm{CN} 2$ (Temperature range: $10^{\circ} \mathrm{C}-60^{\circ} \mathrm{C}$, spectral range: $3-5 \mu \mathrm{m}, 8-$ $12 \mu \mathrm{m})$.

The objective is to record infrared images from both black bodies each heated at different target temperature values; $\mathrm{T}_{\mathrm{CN}_{1}}(\mathrm{i})$ and $\mathrm{T}_{\mathrm{CN} 2}(\mathrm{j})$ with $\mathrm{i} \neq \mathrm{j}$.

For each configuration, measurements are recorded in order to get images of about 3000 lines.

Therefore the duration has been determined considering the stability of each black body. For each couple $\left(\mathrm{T}_{\mathrm{CN} 1}(\mathrm{i}), \mathrm{T}_{\mathrm{CN} 2}(\mathrm{j})\right)$, up to 3 recordings are performed.

As a first issue of each aerial mission, all the images recorded in effective temperature, are later evaluated for validating the results and making the analysis more accurate [2].

\subsection{Airplane}

Before performing any aerial mission, it is mandatory to respect some basic rules.

First the airplane has to be perfectly equipped with the infrared scanner and all control, navigation and recording systems. Secondly the airplane must fulfil in strict criteria for flying (Figure 2). This means that the pilot got all the administrative authorizations from the public authorities and sometimes from the military authorities too.
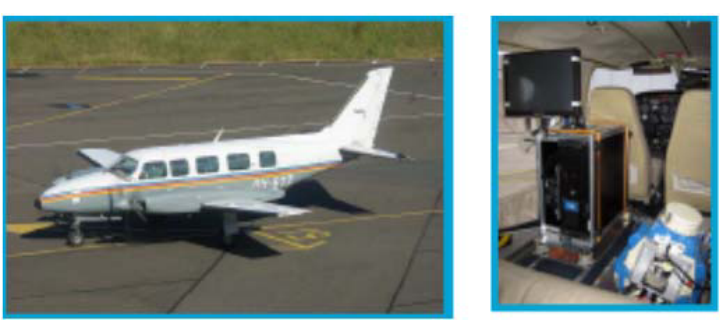

Figure 2: Airplane and Remote sensing system

\subsection{Weather forecast}

Then the weather parameters are the main critical aspects to be accurately checked.

The mission can only be performed respecting the following ideal criteria.

The ideal atmospheric conditions have to be considered as the followings:

- Cold weather, with low ground temperature,

- Wind with limited speed,

- Low relative humidity in order to avoid the accumulation of ice on the upper surface of the roofs or the rooftops of the buildings,

- Dry roofs or rooftops or any material used for residential roofing;

1) Very low rainfalls during a 36 hours period before the flight are highly recommended.

2) No snow is also mandatory evidence.

- Clear sky: good visibility.

\begin{tabular}{|l|l|}
\hline Obj $\mathbf{~}$ & Mission objectives - Climatic targets \\
\hline Obj 1 & Ground temperature, ideally $<5^{\circ} \mathrm{C}$ \\
\hline Obj 2 & Wind speed, ideally $<10 \mathrm{~km} / \mathrm{h}$ \\
\hline Obj 3 & Low humidity \\
\hline Obj 4 & No snow \\
\hline Obj 5 & No fog \\
\hline
\end{tabular}

Table 1: Mission Objectives Summary Weather forecasts provided for instance by a society like "Meteo France" are of a great support and help. Details provided by such a forecast sheet (Figure 3) can allow selecting date and time more accurately for deciding to start or postpone a mission. 


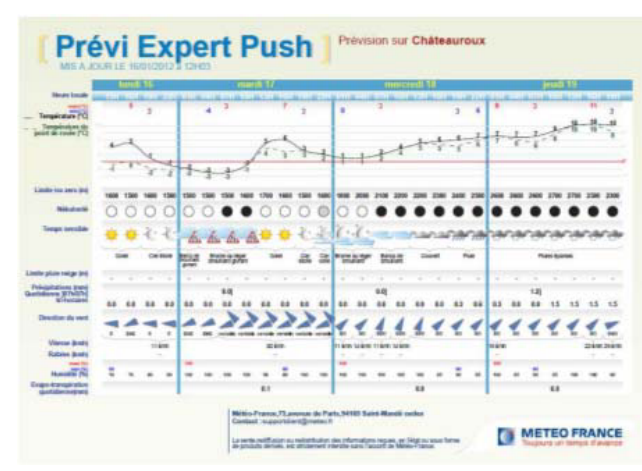

Figure 3: Weather forecast example (source: Meteo France)

\subsection{Seasons, limitations and constraints}

The climatic conditions described $\S .3 .3$ are not the only targets enabling to ideally perform the mission. The following important points have to be considered:

- In France, weather forecasts as described in the previous chapter are usually achieved during the period (middle of November /middle of March)

- Flight has to be perform during the night in order to avoid the direct impact of solar radiation

- Mission has to avoid flying during the week-end and student holydays. During this period the heating systems of schools, universities...are generally not or less working. Idem for the residential houses or buildings.

- Heating systems and thus buildings should be working more or less as close as possible to a steady state regime.

\section{Performing the mission}

\subsection{Flight and recording principles}

The overflight of the territory is made with a twin-engine plane (required for a night flight). This airplane is equipped with an adapted aperture for setting up the infrared scanner.

This system enables to analyze lines perpendicular to the plane displacement.

Each acquisition covers on the ground a footprint band, $500 \mathrm{~m}$ wide. However to keep a recovery rate of about $50 \%$ of each flight strips, the distance between two axes is fixed at about $250 \mathrm{~m}$. (Figure 4)

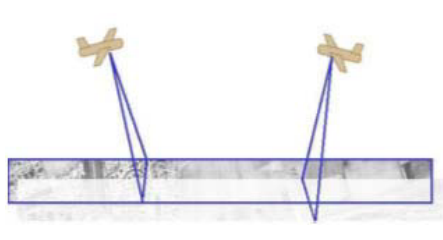

Figure 4: Acquisition configuration

Geo-referencing data are provided by a positioning and orientation system of the scanner with monitoring flight lines (GPS). This system is coupled to an inertial unit.

Considering a four hours mission performed at an altitude of about $500 \mathrm{~m}$ and with an average speed of about $180 \mathrm{~km} / \mathrm{h}$, it is possible to cover about 100 up to $130 \mathrm{~km}^{2}$ [3].

\section{Infrared thermography - Results}

The mission addresses the following scientific and technical issues;

\subsection{Visible Images}

Photo-aircraft is used to superimpose the thermographic mapping (Figure 5) for a more comprehensive cartographic representation of the territory.

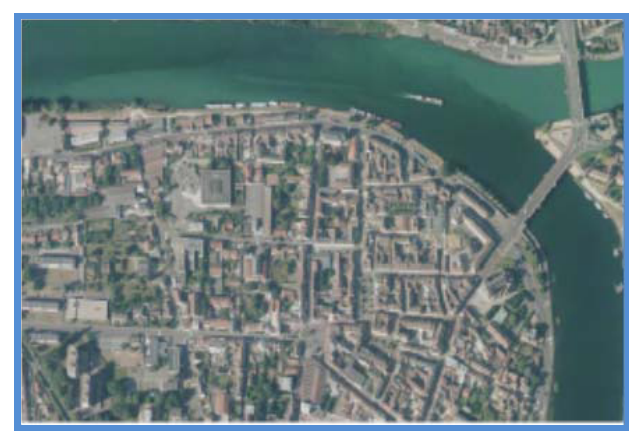

Figure 5: Visible image - example

This information layer, on which the thermographic image can be superimposed, allows easy identification and location of buildings during the presentation of the results to the local authorities.

The visible mapping is also an essential indicator to correctly help and analyse the results of the infrared thermography.

It enables visualizing the type of roof (slope roofing materials), the presence of skylights, solar panels, air outlets and masks (close facades, trees).

As the cadastral layer, the layer provided by the local community may have defects update (according to its acquisition date): e.g. for new constructions that are not visible. Therefore 
this set of visible images is useful for crossing or completing the data base.

\subsection{Infrared thermography}

The infrared thermographic mapping built onto the extracted layer is obtained from the cadastral layer and the overlay with the visible mapping.

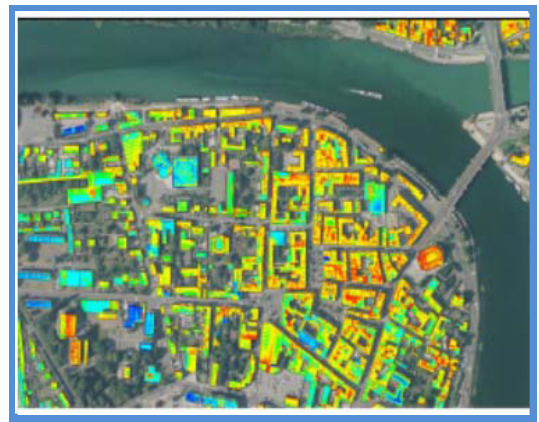

Figure 6: Infrared mapping

(Extracted thermography - 256 colour layer)

This image is a complete and synthetic representation of heat losses from the roofs of buildings. These are represented on the basis of a simplified colour scale: blue (lowest losses) to red (highest losses). (Figure 6)

According to the technical and scientific experience, this basic representation appears as an adapted tool for exploiting the results. This provides a sufficient readability and ease visualization of buildings and its environment. However, we will see in the following chapter, main precautions to be taken before any reporting to the local authorities.

It should be noticed that the extracted infrared thermography is an ortho-rectified and georeferenced image. This mapping can thus be merged into a Geographic Information System (GIS).

\section{Precautions analysis}

Even the infrared thermography technique seems really attractive for helping the local authorities; there is an important set of precautions to take into account before any interpretation [4].

\subsection{Mapping and analysis}

It should be mentioned that the origin of the heat losses is mainly the temperature difference $\Delta T$ between the inside and the outside of the building. The heat spreads spontaneously from the warm environment to the cold environment. The level of heat losses is proportional to this difference DT, and the quality of the thermal insulation.

This thermal insulation is characterized by a thermal resistance for each wall.

The mapping analysis has thus to take care about the building construction, nature and shape of each building's envelope, etc...

\subsection{Infrared thermography - pro and cons}

Aerial thermography enables to observe heat losses which depend on several parameters:

- Type of roof (Figure 7): roofing material, slope, solar panels, photovoltaic or solar thermal systems

- Type of attic (Figure 8): arranged, not arranged, landscaped, heated or non-heated... - Insulation: nature, condition of insulation, thickness

- Thermal bridges, air leaks, ventilation,

- Heating: indoor temperature (impact during the night), chimney...

- Environmental parameters: outdoor temperature, wind, masks

(Common wall with a neighbour, nearby buildings, trees...)

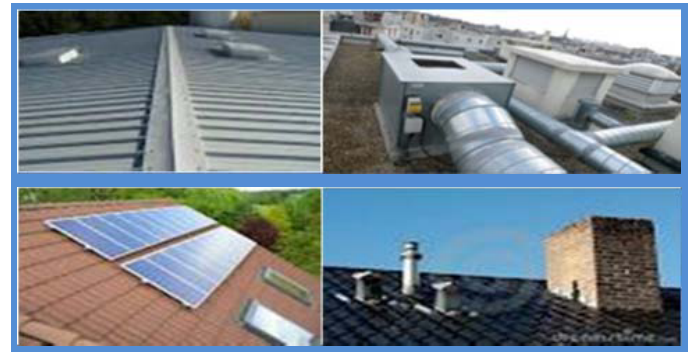

Figure 7: Type of roof

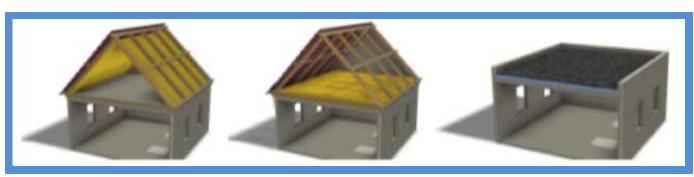

Figure 8: Attic (heated, non-arranged, terrace-roof)

As example, a house with non-arranged attic should appear as "cold" due to the fact that the roof is an unheated part and often cooled by outside air infiltration. Otherwise, this means that the insulation of the floor is not sufficient. In the opposite situation, a house with arranged and heated attic will show more losses through the roof.

Figure 9, we highlight the purpose with a practical example. Both constructions made at the same period and on the basis of a similar 
architecture show an important thermal difference.

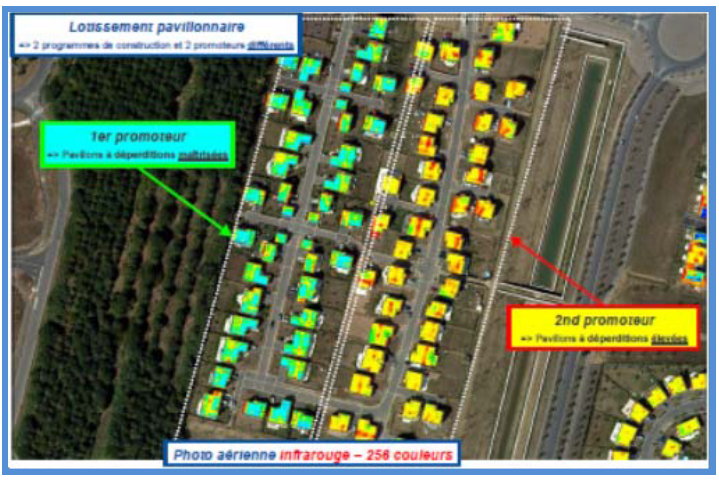

Figure 9: Insulating differences

This mapping and additional discussions with the citizen and the local authorities have enable to confirm that the insulating materials and the method used and applied for both constructions were different.

\section{Conclusions}

Based on a significant experience in the area of radiation thermometry, especially for the "mise en pratique" of the ITS-90 scale and also in the metrology of thermal properties of materials for the realization of derived thermal quantity scales (i.e. emissivity of materials), LNE has developed different remote sensing equipment.

This investigating method aims finally to:

- propose traceable and accurate capabilities

- strengthen the technical protocols with new or better data exploitation methods and metrology capacities.

Infrared thermography with support of the facilities developed within the framework of thermal metrology at LNE is thus a key factor for improving the accuracy of the measurements performed. Therefore, data, mappings and analysis practically allow proposing to the public authorities a more relevant consultancy useful for better managing the building energy efficiency and the environmental impact.

Finally, beyond the scientific and technical objectives of such a mission as described in the previous chapters, the general impact of this service is to provide traceable data and an efficient help to the local authorities for deciding priorities; Priorities for the renovating actions and also for convincing the citizen to renovate and finally for contributing to improve the energy efficiency of the buildings.

The thermal equipment manufacturers as well as for instance the building industry and insulating materials manufacturers can also take advantage of such actions.

\section{Acknowledgements}

The infrared remote sensing system used for the missions was funded through the own LNE Research founding programme.

\section{References}

[1] 2012-2016 Climate and Development Intervention Framework, Agence Française de Développement, 2012

[2] Radiometric calibration procedure of the LNE aerial infrared scanner. V. Le Sant, Internal LNE notice, 2013

[3] Henry J.-B., Pierrard S., Bassi D., Lecadre S., Paraire M., Leclerc S., Mortelette R., Ridoux P., Filtz J.-R., Aerial infrared thermography of cities for energy leaks mapping, Proceedings of the 33rd Symposium on Remote Sensing of the Environment, Stresa, Italy, 2009

[4] Une opération de thermographie aérienne pour mettre en place une OPAH, Témoignage de la communauté d'agglomération du Soissonnais, LNE, 2011 